\title{
Effects of dietary incorporation of different antioxidant extracts and free-range rearing on fatty acid composition and lipid oxidation of Iberian pig meat
}

\author{
E. González ${ }^{1}$ and J. F. Tejeda ${ }^{2+}$ \\ ${ }^{1}$ Animal Production, Escuela de Ingenierías Agrarias, Universidad de Extremadura, Ctra de Cáceres s/n, 06071 Badajoz, Spain; ${ }^{2}$ Food Technology and \\ Biochemistry, Escuela de Ingenierías Agrarias, Universidad de Extremadura, Ctra de Cáceres s/n, 06071 Badajoz, Spain
}

(Received 11 October 2006; Accepted 13 April 2007)

\begin{abstract}
This investigation was designed to evaluate the effects of feeding either free range or in confinement using concentrated diets with the same ingredients and oil source (5.5\% of olive oleins) but with different antioxidant supplementation [control diet with a basal level of $\alpha$-tocopheryl acetate (control); $200 \mathrm{mg} / \mathrm{kg}$ synthetic all-rac- $\alpha$-tocopheryl acetate $\left(E_{\text {all-rac }}\right) ; 200 \mathrm{mg} / \mathrm{kg}$ natural RRR- $\alpha$-tocopheryl-acetate ( $\left.E_{\mathrm{RRR}}\right)$ ); flavonoid extract-enriched diet $\left(A_{\text {Flav }}\right)$; and phenolic compound-enriched extract $\left.\left(A_{\text {Phen }}\right)\right]$ on the fatty acid composition and lipid oxidation of Iberian pig muscle longissimus dorsi. The $\alpha$-tocopherol concentration was significantly higher in muscles from free-range and $E_{R R R-}$ pigs than in muscles from $E_{\text {all-rac }}$ pigs, and $\gamma$-tocopherol was only detected in muscles from free-range pigs. Longissimus dorsi muscles from free-range pigs had a significantly lower content of saturated fatty acids and higher content of polyunsaturated fatty acids than muscles from the other five groups of pigs fed in confinement; however, no significant effect on monounsaturated fatty acids was observed. No effect of dietary antioxidant supplementation (synthetic or natural $\alpha$-tocopherol, flavonoid extract, or phenol extract) on the fatty acid composition of muscles was observed. A significant influence of dietary treatment on lipid oxidation was observed after $3(\mathbb{P}<0.01)$, and 7 and $10(\mathrm{P}<0.001)$ days of refrigerated storage, respectively. The lowest thiobarbituric acid-reactive substances (TBARS) values were found in pork chops from the free-range and $E_{\mathrm{RRR}}$ - groups, intermediate values from the $E_{\text {all-rac }}$ group, followed by $A_{\text {Flav }}$ and $A_{\text {Phen, }}$ while the highest TBARS values corresponded to muscles from pigs fed the control concentrate. The source of $\alpha$-tocopherol had a significant effect on lipid oxidation $(\mathbb{P}<0.05)$, whereas the $A_{\text {Flav }}$ and $A_{\text {Phen }}$ groups had similar TBARS values.
\end{abstract}

Keywords: fatty acids, Iberian pigs, oxidation, phenolic compounds, tocopherols

\section{Introduction}

Peroxidative changes in meat are initiated at the membrane level and are considered one of the main causes of functional, sensory and nutritional quality deterioration in meat and meat products (Morrisey et al., 1998). Nevertheless, lipid oxidation also has positive implications, since some of the volatile compounds that show pleasant flavour notes in Iberian dry-cured meat products arise from oxidation of unsaturated fatty acids (López et al., 1992; Carrapiso et al., 2002). Vitamin $E$, mainly in the form of $\alpha$-tocopherol, is considered to be the principal antioxidant defence agent against lipid oxidation in cell membranes in mammals. It is capable of breaking the chain of lipid oxidation in the cell membranes, thereby preventing the formation of rancid

\footnotetext{
${ }^{\dagger}$ E-mail: jftejeda@unex.es
}

flavour during storage (Buckley et al., 1995). The naturally occurring form of $\alpha$-tocopherol is stereoisomer $R R R-\alpha$ tocopherol. Free-range rearing of Iberian pigs, based on acorns and grass, provides a source of natural $\alpha$-tocopherol and $\gamma$-tocopherol in muscle with subsequent positive effect on the susceptibility of tissues to lipid oxidation (Rey et al., 1998; González et al., 2006). However, it is not always possible to feed the Iberian pigs extensively, and hence it is common to employ concentrated feeds for fattening them (López-Bote, 1998). Supplemental vitamin E is usually added to animal feed in the form of all-rac- $\alpha$-tocopheryl acetate. Synthetic $\alpha$-tocopherol (all-rac- $\alpha$-tocopherol) is an equimolecular mixture of eight isomers (Vitamin E Research and Information Service, 1997), only one of which is identical to the naturally occurring stereoisomer, $R R R$ - $\alpha$-tocopherol. The advantages of vitamin $E$ supplementation at supranutritional levels in the diet of pigs in terms of 
increasing the oxidative stability of lipids in muscle have been widely shown (Buckley et al., 1989; Rey et al., 2004; Ventanas et al., 2006).

As for the use of antioxidants, there has been burgeoning interest in plant-based extracts as sources of natural phenolic antioxidants. Plant (poly)phenols are a diverse group of compounds that mainly include simple phenols, phenolic acids, coumarins, tannins and flavonoids. In this context, several studies on the potential of herbs and spices as natural antioxidants have been reported (see, for instance, the review by Madsen and Bertelsen, 1955), and generally rosemary, sage and clove are considered to be among the strongest antioxidative spices. However, a great number of other plant sources have been reported as potentially natural antioxidants, e.g. grapes, green tea and various vegetables. In this context, Cantos et al. (2003) analysed and identified 32 different phenolic compounds belonging to acorns consumed by lberian pigs in extensive systems, and they estimated that a pig can ingest between 14 and $20 \mathrm{~g}$ of polyphenols from acorns every day, which could also contribute to reduce lipid oxidation in meat from free-range Iberian pigs. González et al. (2004) report higher amounts of phenolic compounds in the adipose tissue of Iberian pigs fed exclusively on natural resources (acorns and grass) than those fed on concentrated diets. In general, the effect of a certain potential antioxidant might vary considerably depending on a complex interaction between various factors, involving the type and concentration of active compounds and on the nature of the feeding system (Schwarz et al., 2001; Skerget et al., 2005).

The objective of the present work was to evaluate the antioxidative activity of three extracts with different antioxidant components when incorporated into a concentrated feed compared with a control diet, a synthetic vitamin $E$ supplemented diet, and a free-range diet based on acorns and grass, using measurements of thiobarbituric acid-reactive substances (TBARS), fatty acid composition, tocopherols and phenolic compound content in longissimus dorsi muscle of Iberian pigs.

\section{Material and methods}

\section{Animals and diets}

In all, 48 castrated male Iberian $\times$ Duroc pigs were selected at $98 \pm 6 \mathrm{~kg}$ live weight, with an age of 10 months, and randomly allotted into six groups $(n=8)$. One group was free-range-reared according to the traditional way in which the hogs feed on natural resources (acorns and grass) for 81 days from November to February, when the maturation of acorns (Quercus ilex and Quercus suber) takes place. The other five groups of pigs were assigned at random to one of the following olive olein (5.5\%)-enriched diets for 94 days in confinement, and were fed ad libitum: control diet containing a basal level of $\alpha$-tocopheryl acetate ( $20 \mathrm{mg} / \mathrm{kg}$ diet; Hoffman La Roche, Switzerland) (control); synthetic all-rac- $\alpha$-tocopheryl acetate-enriched diet $\left(200 \mathrm{mg} / \mathrm{kg}\right.$ feed) ( $\mathrm{E}_{\text {all-radi }}$; natural $R R R$ $\alpha$-tocopherol extract-enriched diet ( $200 \mathrm{mg} / \mathrm{kg}$ feed) $\left(\mathrm{E}_{R R R-}\right)$; diet enriched with $2 \mathrm{~g} / \mathrm{kg}$ feed of commercial preparation of flavonoid extract (mainly composed of grapes, nuts and citrus fruits) $\left(A_{\text {Flav }}\right)$; diet enriched with $8 \mathrm{~g} / \mathrm{kg}$ feed of commercial preparation of phenolic-enriched extract (dried chestnut powders) $\left(A_{\text {phen }}\right)$. Pigs were stunned and slaughtered at a local slaughterhouse after the fattening period at a live weight of $163 \pm 7 \mathrm{~kg}$ and at an age of 12 months and 21 days for pigs fed in confinement with concentrates, and at 13 months and 4 days for free-range-reared pigs.

The compositional analysis of acorns, grass and feed concentrates was determined according to the methods of Association of Official Analytical Chemists (1984). Nitrogenfree extractive contents were calculated by difference. Fatty acids in the diets were analysed by gas chromatography after lipid extraction according to the Bligh and Dyer (1959) method and acidic-trans-esterification (Cava et al., 1997). $\alpha$-tocopherol and $\gamma$-tocopherol were determined following the method described by Buttris and Diplock (1984). Phenolic compounds were determined according to the method of Vázquez et al. (1973).

\section{Sampling}

Longissimus dorsi muscle was dissected from each carcass, and freed of visible fat. Samples of this muscle were taken at cutting ( $24 \mathrm{~h}$ after slaughter) at the level of the last rib, vacuum-packed, and frozen at $-80^{\circ} \mathrm{C}$ until analysis. Analyses were carried out in duplicate within 4 weeks of slaughter, except that samples for TBARS values were analysed on days 1, 3, 7 and 10 after slaughter.

\section{Lipid extraction and fatty acid composition}

Intramuscular lipids were extracted with a mixture of chloroform/methanol (1:2) according to the method described by Bligh and Dyer (1959). Solvent was removed under vacuum on a rotary evaporator, lipid extracts were weighed, and the results were expressed as $\mathrm{g} / 100 \mathrm{~g}$ fresh muscle. The fatty acid composition of lipids was determined by gas chromatography after acidic-trans-esterification in the presence of sulphuric acid (5\% sulphuric acid in methanol) (Cava et al., 1997). The gas chromatograph (Hewlett-Packard 4890 Series II, Hewlett-Packard, Avondale, PA, USA) was equipped with a split/splitless injector and a flame-ionisation detector. Fatty acid methyl esters (FAMEs) were separated on a nitroterephthalic acid-modified polyethylene glycol (HP-FFAP)modified fused silica semicapillary column $(30 \mathrm{~m}$ long, $0.53 \mathrm{~mm}$ i.d., $1 \mu \mathrm{m}$ film thickness) maintained at $230^{\circ} \mathrm{C}$. Injector and detector temperatures were $280^{\circ} \mathrm{C}$. Nitrogen was used as carrier gas at $1.8 \mathrm{ml} / \mathrm{min}$. The individual FAMEs were identified by comparison of their retention times with those of reference standard mixtures (Sigma Chemical Co., St Louis, MO, USA). Results were expressed as $\mathrm{g} / 100 \mathrm{~g}$ of the total fatty acid methyl esters.

\section{Determination of tocopherols in muscle}

The $\alpha$-tocopherol and $\gamma$-tocopherol in muscle were determined following the method described by Rey et al. (1996). 
Muscle $(0.8 \mathrm{~g})$ was homogenised in $6 \mathrm{ml} 0.054 \mathrm{~mol} / /$ dibasic sodium phosphate buffer adjusted to $\mathrm{pH} 7.0$ with $\mathrm{HCl}$. After mixing with absolute ethanol and hexane, the upper layer containing tocopherols was evaporated to dryness and dissolved in $200 \mu$ l ethanol prior to analysis by reversephase high-performance liquid chromatography (HPLC; Agilent 1100 Series, with a diode array detector, Agilent Technologies, Wilmington, DE, USA). Separation was done on a Lichrospher RP-C18 column (Agilent Technologies) ( $250 \mathrm{~mm} \times 4 \mathrm{~mm}$ i.d., $5 \mu \mathrm{m}$ particle size), the mobile phase was with methanol:water $(97: 3 \mathrm{vol} / \mathrm{vol})$ at a flow rate of $2 \mathrm{ml} / \mathrm{min}$, and peaks were registered at $292 \mathrm{~nm}$. The peaks were identified and quantified by calibration with $\alpha$ - and $\gamma$-tocopherol standards (Sigma Chemical Co.).

\section{Determination of phenols in muscle}

Phenolic compounds were isolated using the modified method described by Vázquez et al. (1973) with triple extraction of an oil-in-hexane solution with a $80 \% \mathrm{vol} / \mathrm{vol}$ water/methanol mixture. The concentration of total polyphenols was estimated with Folin-Ciocalteau reagent at $725 \mathrm{~nm}$. Results were expressed as $\mu \mathrm{g}$ of caffeic acid per $\mathrm{g}$ of muscle. This method of analysis of phenols is quantitative, and does not distinguish the different species of phenols present in the commercial extracts used.

\section{Thiobarbituric acid-reactive substances number}

TBARS were evaluated to determine the effects of the experimental diets on oxidative stability in meat samples on days $1,3,7$ and 10 of refrigerated $\left(4^{\circ} \mathrm{C}\right)$ storage. Pork chops of longissimus dorsi muscle weighing approximately $40 \mathrm{~g}$ were placed and over-wrapped with an oxygen-permeable PVC wrap and stored at $4^{\circ} \mathrm{C}$ under fluorescent light. The extent of lipid oxidation was estimated as TBARS according to the Salih et al. (1987) method. TBARS were expressed as nmol malonaldehyde per mg meat.

\section{Statistical analysis}

All data were analysed by one-way analysis of variance using the general linear model of Statistical Packages for the Social Sciences (2003) statistical software. An individual pig was the experimental unit for the analysis of all data. Data were expressed as the mean of each group and the pooled standard error of the mean together with the significance levels of the effect. When a significant probability was detected $(P<0.05)$, paired comparisons between means were carried out using the Tukey test.

\section{Results and discussion}

\section{Experimental diets}

The chemical and major fatty acid composition of the basal feed concentrate, acorns and grass are given in Table 1. Acorns are characterised by a very high content of nitrogenfree extractives $(83.3 \mathrm{~g} / 100 \mathrm{~g}$ dry matter (DM)) and fat $(7.3 \mathrm{~g} / 100 \mathrm{~g} \mathrm{DM})$, and consequently with a very high level

Table 1 Chemical composition ( $\mathrm{g} / 100 \mathrm{~g}$ dry matter) and main fatty acids (g/100 $\mathrm{g}$ fatty acids) of the experimental diets

Concentrate feed Acorns Grass

Chemical composition

Dry matter (DM, g/100 g feed)

92.5

15.8

6.5

Crude fat $(g / 100 \mathrm{~g} \mathrm{DM})$

Crude fibre (g/100 g DM)

Ash (g/100 g DM)

Nitrogen-free extractives (g/100 g DM)

Fatty acids ( $\mathrm{g} / 100 \mathrm{~g}$ fatty acids)

C16:0
C16:1 $(n-7)$
C17:0
C17:1 $(n-7)$
C18:0
C18:1 $(n-9)$
C18:2 $(n-6)$
C18:3 $(n-3)$
C20:0
C20:1 $(n-9)$
$\sum$ Saturated
$\sum$ Monounsaturated
$\sum$ Polyunsaturated

\begin{tabular}{rrr}
14.38 & 14.93 & 19.83 \\
0.69 & 0.40 & 1.48 \\
0.11 & 0.27 & 0.59 \\
0.11 & 0.09 & 0.80 \\
3.50 & 3.69 & 6.25 \\
54.74 & 59.55 & 18.92 \\
23.33 & 18.73 & 10.63 \\
1.97 & 1.37 & 40.51 \\
0.47 & 0.48 & 0.65 \\
0.51 & 0.50 & 0.33 \\
18.65 & 19.37 & 27.32 \\
56.05 & 60.54 & 21.53 \\
25.30 & 20.09 & 51.15 \\
\hline
\end{tabular}

of energy, but with a very low concentration of protein $(5.1 \mathrm{~g} / 100 \mathrm{~g} \mathrm{DM})$. Grass is needed as a source of protein $(25.3 \mathrm{~g} / 100 \mathrm{~g} \mathrm{DM})$ and fibre $(18.4 \mathrm{~g} / 100 \mathrm{~g} \mathrm{DM})$ to compensate for the low concentration of these nutrients in acorns. The nutritive value of the concentrates is in accordance with the standards used in Iberian pigs. The fatty acid composition of the diets are in agreement with values previously reported in studies involving the feeding of Iberian pigs (Cava et al., 2000; González et al., 2006; Ventanas et al., 2006) with a higher level of monounsaturated and a lower level of polyunsaturated fatty acids in acorns than in the diet concentrate and grass. Even compared with the oleic acid-enriched diet concentrate, acorns had a higher content of C18:1 $n-9$ than the concentrate $(59.55$ v. $54.74 \mathrm{~g} / 100 \mathrm{~g}$ fatty acids). Grass was characterised by a relatively high proportion of C18:3 $n-3$ ( $40.51 \mathrm{~g} / 100 \mathrm{~g}$ fatty acids). The diet concentrate had higher proportions of C18:2 n-6 than acorns and grass.

Table 2 shows the $\alpha$-tocopherol, $\gamma$-tocopherol, and total phenolic compounds found in the five mixed diets, acorns and grass. The $\mathrm{E}_{\text {all-rac }}$ and $\mathrm{E}_{R R R-}$ concentrates had the highest contents of $\alpha$-tocopherol ( 260.5 and $286.7 \mathrm{mg} / \mathrm{kg}$, respectively), similar to grass $(271.4 \mathrm{mg} / \mathrm{kg})$. Coherent with these results, Daza et al. (2005) reported comparable $\alpha$-tocopherol contents in grass with those in supplemented concentrate diets. With respect to $\gamma$-tocopherol, acorns had higher levels $(60.7 \mathrm{mg} / \mathrm{kg})$ than concentrated diets $(4.7$ to $6.0 \mathrm{mg} / \mathrm{kg}$ ), in agreement with previously reported data (Rey et al., 1998; Daza et al., 2005; González et al., 2006). 
Table 2 Antioxidant concentrations in the experimental diets

\begin{tabular}{|c|c|c|c|c|c|c|c|}
\hline & \multicolumn{5}{|c|}{ Concentrate feed ${ }^{\dagger}$} & \multicolumn{2}{|c|}{ Free range } \\
\hline & Control & $\mathrm{E}_{\text {all-rac }}$ & $\mathrm{E}_{R R R-}$ & $A_{\text {flav }}$ & Aphen & Acorns & Grass \\
\hline$\alpha$-tocopherol (mg/kg DM) & 42.3 & 260.5 & 286.7 & 33.3 & 31.7 & 4.4 & 271.4 \\
\hline$\gamma$-tocopherol (mg/kg DM) & 6.0 & 4.7 & 4.9 & 4.8 & 5.7 & 60.7 & nd \\
\hline Total phenols (g/kg DM) & 1.16 & 1.16 & 1.10 & 1.17 & 1.62 & 9.00 & 16.94 \\
\hline
\end{tabular}

$\mathrm{DM}=$ dry matter; $\mathrm{nd}=$ not determined.

${ }^{+}$Control: basal diet containing a basal level of $\alpha$-tocopheryl acetate $(20 \mathrm{mg} / \mathrm{kg}$ diet). Eall-rac basal diet enriched with $200 \mathrm{mg} / \mathrm{kg}$ diet of synthetic all-rac- $\alpha$ tocopheryl acetate. $\mathrm{E}_{R R R \text { : }}$ basal diet enriched with $200 \mathrm{mg} / \mathrm{kg}$ diet of natural $R R R$ - $\alpha$-tocopheryl acetate. A $A_{\text {Flav: }}$ basal diet enriched with $2 \mathrm{~g} / \mathrm{kg}$ diet of commercial preparation of flavonoid extract. Aphe: basal diet enriched with $8 \mathrm{~g} / \mathrm{kg}$ diet of commercial preparation of polyphenol extract.

Table 3 Chemical composition ( $\mathrm{g} / 100 \mathrm{~g}$ muscle) and antioxidant concentration ( $\mu \mathrm{g} / \mathrm{g}$ of fresh matter) in longissimus dorsi muscle from Iberian pigs fed in confinement with the experimental diets or in free-range conditions

\begin{tabular}{|c|c|c|c|c|c|c|c|c|}
\hline & \multicolumn{6}{|c|}{ Treatment $^{\dagger}$} & \multirow[b]{2}{*}{ s.e. } & \multirow[b]{2}{*}{ Significance } \\
\hline & Control & $\mathrm{E}_{\mathrm{all}-r a c}$ & $\mathrm{E}_{R R R-}$ & $A_{\text {flav }}$ & $A_{\text {Phen }}$ & FR & & \\
\hline$n$ & 8 & 8 & 8 & 8 & 8 & 8 & & \\
\hline \multicolumn{9}{|c|}{ Chemical composition ( $\mathrm{g} / 100 \mathrm{~g}$ of muscle) } \\
\hline Moisture & 67.34 & 69.52 & 68.19 & 68.76 & 68.55 & 69.19 & 0.40 & NS \\
\hline Crude protein & $22.62^{\mathrm{a}}$ & $22.22^{\mathrm{ab}}$ & $22.74^{\mathrm{a}}$ & $22.77^{\mathrm{a}}$ & $22.86^{\mathrm{a}}$ & $21.33^{b}$ & 0.12 & $* * *$ \\
\hline Intramuscular fat & 8.97 & 7.23 & 8.02 & 7.41 & 7.52 & 8.54 & 0.40 & NS \\
\hline Ash & $1.08^{a}$ & $1.04^{\mathrm{a}}$ & $1.05^{\mathrm{a}}$ & $1.06^{\mathrm{a}}$ & $1.07^{\mathrm{a}}$ & $0.94^{b}$ & 0.01 & $* * *$ \\
\hline \multicolumn{9}{|l|}{ Antioxidants $(\mu \mathrm{g} / \mathrm{g})^{\ddagger}$} \\
\hline$\alpha$-tocopherol & $0.96^{\mathrm{c}}$ & $2.05^{\mathrm{b}}$ & $3.05^{\mathrm{a}}$ & $0.88^{c}$ & $1.10^{c}$ & $2.90^{\mathrm{a}}$ & 0.14 & $* * *$ \\
\hline$\gamma$-tocopherol & nd & nd & nd & nd & nd & 0.32 & & $* * *$ \\
\hline Total phenols & 176.19 & 195.81 & 170.52 & 183.27 & 177.50 & 162.23 & 3.92 & NS \\
\hline
\end{tabular}

$\mathrm{a}, \mathrm{b}, \mathrm{c}$ Means in the same row, means with different superscripts differ significantly. Significance levels: ${ }^{* *}=P<0.001$. NS $=P>0.05$.

$\mathrm{FR}=$ free-range rearing based on acorns and grass; NS = not significant; $\mathrm{nd}=$ not determined.

${ }^{+}$Control: basal diet containing a basal level of $\alpha$-tocopheryl acetate $\left(20 \mathrm{mg} / \mathrm{kg}\right.$ diet). Eall-rac $_{\text {i }}$ basal diet enriched with $200 \mathrm{mg} / \mathrm{kg}$ diet of synthetic all-rac- $\alpha$ tocopheryl acetate. $E_{R R R \text { : }}$ basal diet enriched with $200 \mathrm{mg} / \mathrm{kg}$ diet of natural $R R R$ - $\alpha$-tocopheryl acetate. Aflav: basal diet enriched with $2 \mathrm{~g} / \mathrm{kg}$ diet of commercial preparation of flavonoid extract. Aphe: basal diet enriched with $8 \mathrm{~g} / \mathrm{kg}$ diet of commercial preparation of polyphenol extract.

FExpressed as fresh matter.

Analysis of total phenolic compounds showed a higher content in grass $(16.9 \mathrm{~g} / \mathrm{kg})$ than in acorns $(9.0 \mathrm{~g} / \mathrm{kg})$. To the best of our knowledge, there are no published studies comparing total phenolic compounds in grass and acorn. Cantos et al. (2003) report the total phenolic contents in acorns of 1.4 to $2.2 \mathrm{mg} / \mathrm{kg}$, values clearly lower than in our study probably due to the different methods of analysis. With respect to the concentrates, the $A_{\text {phen }}$ mixed diet had a higher total phenolic content $(1.62 \mathrm{~g} / \mathrm{kg})$ than other concentrated diets $(1.10$ to $1.17 \mathrm{~g} / \mathrm{kg})$ as a result of the incorporation of phenolic compound extracts.

\section{Muscle composition}

The influence of the experimental diets applied during the fattening period of Iberian pigs on the chemical composition and antioxidant content of longissimus dorsi muscle is presented in Table 3. No significant effect was observed on moisture and intramuscular fat. Meat from pigs fed on experimental concentrated diets had a significantly higher content of ash and crude protein than that from freerange pigs.

The $\alpha$-tocopherol content of the muscle was also affected by diets. Generally, it reflected the tocopherol concentration of the diets, being significantly higher $(P<0.001)$ in the longissimus dorsi muscle of pigs fed on the natural tocopherol-enriched diet $\left(E_{R R R}\right)$ and free-range system than those fed on non- $\alpha$-tocopherol-enriched diets (control, $A_{\text {Flav }}$ and $\left.A_{\text {Phen }}\right) ;$ the $200 \mathrm{mg} / \mathrm{kg}$ diet synthetic $\alpha$-tocopheryl acetate-enriched diet $\left(\mathrm{E}_{\text {all }}\right.$-rad gave intermediate values $(2.05 \mu \mathrm{g} / \mathrm{g})$. These findings may be due to a higher consumption of vitamin $\mathrm{E}$ in $\mathrm{E}_{R R R \text { - }}$ and free-range pigs than the non- $\alpha$-tocopherol-enriched diets, in agreement with results previously reported in Iberian pigs (Rey et al., 1998; Cava et al., 2000; González et al., 2006). However, in the $E_{a l l-r a c}$ group the $\alpha$-tocopherol content was significantly lower than in the $\mathrm{E}_{R R R-}$ and free-range groups, although the $\alpha$-tocopherol content of their diets was similar. This fact could be related to the findings of Lauridsen et al. (2002), who reported that natural vitamin $\mathrm{E}$ has roughly twice the 
Table 4 Fatty acid composition ( $\mathrm{g} / 100 \mathrm{~g}$ fatty acids) in longissimus dorsi muscle from Iberian pigs fed in confinement with the experimental diets or in free-range conditions

\begin{tabular}{|c|c|c|c|c|c|c|c|c|}
\hline & \multicolumn{6}{|c|}{ Treatment $^{\dagger}$} & \multirow[b]{2}{*}{ s.e. } & \multirow[b]{2}{*}{ Significance } \\
\hline & Control & $\mathrm{E}_{\text {all-rac }}$ & $\mathrm{E}_{R R R-}$ & $A_{\text {flav }}$ & $A_{\text {Phen }}$ & FR & & \\
\hline$n$ & 8 & 8 & 8 & 8 & 8 & 8 & & \\
\hline C14:0 & 1.55 & 1.48 & 1.58 & 1.58 & 1.54 & 1.49 & 0.013 & NS \\
\hline C16:0 & $26.25^{a}$ & $26.17^{a}$ & $26.55^{a}$ & $26.48^{\mathrm{a}}$ & $26.47^{\mathrm{a}}$ & $24.73^{b}$ & 0.150 & ** \\
\hline C16:1 (n-7) & 4.08 & 3.86 & 4.43 & 4.59 & 4.23 & 4.16 & 0.082 & NS \\
\hline C17:0 & 0.17 & 0.24 & 0.15 & 0.14 & 0.15 & 0.17 & 0.013 & NS \\
\hline C17:1 (n-7) & 0.19 & 0.27 & 0.18 & 0.17 & 0.18 & 0.19 & 0.013 & NS \\
\hline C18:0 & 11.96 & 12.27 & 11.64 & 11.37 & 12.01 & 10.69 & 0.170 & NS \\
\hline C18:1 (n-9) & 50.11 & 50.15 & 50.39 & 50.35 & 50.04 & 51.65 & 0.200 & NS \\
\hline C18:2 $(n-6)$ & $3.74^{\mathrm{a}}$ & $3.56^{\mathrm{a}}$ & $3.31^{\mathrm{a}}$ & $3.55^{\mathrm{a}}$ & $3.54^{a}$ & $4.90^{b}$ & 0.127 & ** \\
\hline C18:3 $(n-3)$ & $0.17^{\mathrm{a}}$ & $0.16^{\mathrm{a}}$ & $0.16^{\mathrm{a}}$ & $0.16^{a}$ & $0.17^{a}$ & $0.33^{\mathrm{b}}$ & 0.010 & $* * *$ \\
\hline C20:0 & 0.18 & 0.18 & 0.18 & 0.17 & 0.19 & 0.16 & 0.004 & NS \\
\hline $\mathrm{C} 20: 1(n-9)$ & $0.84^{\mathrm{ab}}$ & $0.92^{\mathrm{b}}$ & $0.78^{\mathrm{ab}}$ & $0.75^{a}$ & $0.80^{\mathrm{ab}}$ & $0.77^{a}$ & 0.016 & * \\
\hline $\mathrm{C} 20: 2(n-6)$ & $0.14^{\mathrm{a}}$ & $0.14^{\mathrm{a}}$ & $0.12^{a}$ & $0.13^{a}$ & $0.14^{\mathrm{a}}$ & $0.19^{b}$ & 0.004 & $* * *$ \\
\hline $\mathrm{C} 20: 3(n-6)$ & 0.09 & 0.09 & 0.08 & 0.08 & 0.08 & 0.07 & 0.004 & NS \\
\hline C20:4 (n-6) & 0.53 & 0.50 & 0.47 & 0.49 & 0.47 & 0.49 & 0.027 & NS \\
\hline$\sum$ Saturated & $40.11^{\mathrm{a}}$ & $40.35^{a}$ & $40.09^{a}$ & $39.74^{\mathrm{ab}}$ & $40.36^{\mathrm{a}}$ & $37.23^{b}$ & 0.304 & * \\
\hline$\sum$ Monounsaturated & 55.22 & 55.21 & 55.78 & 55.86 & 55.24 & 56.78 & 0.231 & NS \\
\hline$\sum$ Polyunsaturated & $4.67^{\mathrm{ab}}$ & $4.45^{b}$ & $4.13^{b}$ & $4.40^{b}$ & $4.40^{\mathrm{b}}$ & $5.99^{a}$ & 0.160 & ** \\
\hline
\end{tabular}

a,b,c Means in the same row, means with different superscripts differ significantly. Significance levels: ${ }^{*}=P<0.05 ;{ }^{* *}=P<0.01 ;{ }^{* *}=P<0.001$. NS $=P>0.05$. FR: free-range rearing based on acorns and grass.

${ }^{+}$Control: basal diet containing a basal level of $\alpha$-tocopheryl acetate $\left(20 \mathrm{mg} / \mathrm{kg}\right.$ diet). $\mathrm{E}_{\text {all-rac }}$ basal diet enriched with $200 \mathrm{mg} / \mathrm{kg}$ diet of synthetic all-rac- $\alpha$ -

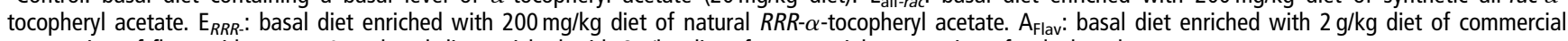
preparation of flavonoid extract. Aphe: basal diet enriched with $8 \mathrm{~g} / \mathrm{kg}$ diet of commercial preparation of polyphenol extract.

activity of synthetic vitamin $E$ in maintaining the plasma concentration in pigs. As with $\alpha$-tocopherol, $\gamma$-tocopherol reflected the concentration of this compound in the diets, and due to the high content of $\gamma$-tocopherol in acorns, it was only identified in muscles of free-range pigs at a level of $0.32 \mu \mathrm{g} / \mathrm{g}$ of muscle, in agreement with data previously described by various authors for Iberian pigs fed under extensive conditions with acorns and grass (Daza et al., 2005; González et al., 2006).

Unexpectedly, the total phenol content in longissimus dorsi muscle was not significantly affected by the type of feeding in confinement or free range studied in this work. Information concerning the occurrence of phenolic compounds in animal tissues is extremely scarce. Estévez et al. (2006) recently reported higher amounts of total phenolic compounds in meat from free-range-reared Iberian pigs than in white pigs fed on concentrates in confinement, which was explained by the intake of grass and acorns by the Iberian pigs compared with white pigs.

Table 4 gives the fatty acid composition of longissimus dorsi muscle. It was significantly different between Iberian pigs fed in free-range rearing conditions and pigs fed in confinement with experimental concentrated diets. Freerange pigs showed significantly $(P<0.05)$ lower saturated fatty acid contents, mainly due to the lower levels of C16:0 $(P<0.01)$, and significantly higher polyunsaturated fatty acids $(P<0.01)$, i.e. $C 18: 2 n-6, C 18: 3 n-3$ and C20:2 $n-6$, than pigs receiving experimental concentrate feeds. These results are in agreement with those reported previously in
Iberian pigs fed on free-range and concentrated diets (Cava et al., 2000; Tejeda et al., 2002; Daza et al., 2005). No significant influence of free-range feeding or experimental diets in confinement on monounsaturated fatty acids, i.e. C18:1 n-9 and C16:1 n-7, was found. Muriel et al. (2002) and González et al. (2006) reported comparable results for the monounsaturated fatty acid composition of Iberian pig muscle using olive oleins as a source of dietary monounsaturated fatty acids. On the contrary, Daza et al. (2005) found significantly higher levels of C18:1 n-9 in lberian pigs fed in free-range rearing conditions than in pigs fed in confinement with monounsaturated-enriched diets. Ventanas et al. (2006), studying oleic-enriched diets and Iberian pigs fed on free range, found similar monounsaturated proportions in phospholipids from the longissimus dorsi muscle in oleic-enriched diet-fed and free-range Iberian pigs, but higher proportions than in non-oleic-enriched pigs. Therefore, monounsaturated proportions of muscles reflected the monounsaturated content in the oleic-enriched and free-range diets. As suggested by those authors, oleicenriched diets thus appear to be a successful strategy to achieve a monounsaturated profile similar to that of freerange-reared pigs, which has been highlighted as one of the main reasons for the high quality of meat products from Iberian pigs (Cava et al., 1999; Ruiz et al., 2002).

The fatty acid composition of longissimus dorsi muscle was not affected by dietary supplementation at supranutritional levels of $\alpha$-tocopherol in feeds ( $\mathrm{E}_{\mathrm{all}}$-rac and $\mathrm{E}_{R R R-}$ ). These results are in accordance with those reported in the 
literature for Iberian (Cava et al., 2000; Daza et al., 2005) and lean (Monahan et al., 1992; López-Bote et al., 1997; Rey et al., 2004) pigs in which $\alpha$-tocopherol-enriched diets did not modify the fatty acid profiles of fat deposits. However, other authors found an effect of $\alpha$-tocopheryl acetate supplementation on $n-9$ fatty acids in pigs (Rey et al., 2001) and chickens (Fuhrmann and Sallman, 1996), results ascribed to a possible effect of the $\alpha$-tocopherol on the $\Delta-9$ desaturase activity (Okayasu et al., 1977). Neither was the fatty acid composition affected by the source of vitamin $E_{\text {, whether natural }}\left(\mathrm{E}_{R R R-}\right)$ or synthetic $\left(\mathrm{E}_{\mathrm{all}}\right.$-rad $)$. We are aware of no published information with regard to the effect of the source of vitamin $E$ on the fatty acid composition of intramuscular lipids of pigs. Similarly, there was no overall effect of the exogenous source of phenolic compounds incorporated into the concentrate diets $\left(A_{\text {phen }}\right.$ and $A_{\text {flav }}$ ) on the fatty acid composition of longissimus dorsi muscle.

\section{Lipid oxidation in muscle}

TBARS values were measured on days 1, 3, 7 and 10 (Figure 1) to evaluate the oxidative stability of longissimus dorsi muscle during refrigerated storage. A significant influence of dietary treatment on lipid oxidation was observed after $3 \quad(P<0.01), 7 \quad(P<0.001)$ and 10 $(P<0.001)$ days of refrigerated storage. The lowest TBARS values were found in pork chops from pigs fed free-range and on $\mathrm{E}_{R R R-}$ concentrate. Intermediate values were presented by samples from pigs fed with $\mathrm{E}_{\mathrm{all}}$-rac concentrate, while the highest TBARS values corresponded to muscles from pigs fed the $A_{\text {Flav, }} A_{\text {Phen }}$ and control concentrates. These results are evidence that diets rich in vitamin $E$ decrease the susceptibility to lipid oxidation in pig longissimus dorsi muscle. The positive effect of vitamin $\mathrm{E}$ on lipid oxidation in the presence of dietary oils has been previously reported in Iberian pigs (Cava et al., 2000) and in

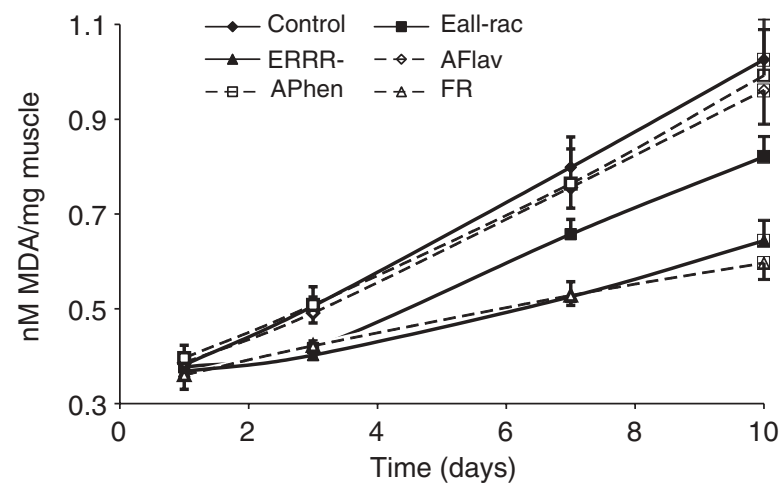

Figure 1 Effect of dietary antioxidant supplementation ( $\mathrm{E}_{\text {all-rac }} \mathrm{E}_{R R R-\text {, }}$ $A_{\text {Flav }} A_{\text {Phen }}$ and Control) and free-range rearing (FR) on lipid oxidation of longissimus dorsi muscle samples from Iberian pigs after refrigerated display at $1,3,7$ and 10 days at $4^{\circ} \mathrm{C}$. Data points are means of TBARS (thiobarbituric acid reactive substances), measured as nmol/l of MDA (malonaldehyde) per mg muscle. Some of the standard error bars lie within the data points. pigs of improved genotypes (Monahan et al., 1992; Rey et al., 2001; López-Bote et al., 2003). Conversely, other authors have reported that supranutritional vitamin $E$ did not decrease TBARS values (Cherian et al., 1996; Daza et al., 2005). Daza et al. (2005) suggested that these discrepancies might be due to differences in either lipid accumulation in tissues or enzyme regulation of the oxidative status.

The lowest TBARS values found in the samples from freerange pigs could have been related to the high $\alpha$-tocopherol content in grass and $\gamma$-tocopherol content in acorns, reflected in the higher concentration of these tocopherol isomers in the muscle $(2.90$ and $0.32 \mu \mathrm{g} / \mathrm{g}$, respectively) (Table 3). These results agree with previous findings by Cava et al. (1999 and 2000) and Ventanas et al. (2006). Furthermore, acorn phenolics could be the 'other dietary constituents' of the diet characteristically used to feed Iberian pigs that might play a role in stabilising lipid oxidation (Cantos et al., 2003). In contrast, other authors have reported higher TBARS values in Iberian pigs fed free range compared with those fed in confinement (Rey and LópezBote, 2001; Daza et al., 2005). The higher oxidation rate of muscles of free-range pigs could be ascribed to their higher myoglobin content (due to exercise) and $n-3$ fatty acid content (Rey and López-Bote, 2001).

TBARS values are lower $(P<0.05)$ on days 3,7 and 10 of refrigerated storage in meat from Iberian pigs fed the concentrated diet enriched with natural $\alpha$-tocopherol extract $\left(\mathrm{E}_{R R R}\right)$ compared with the synthetic $\alpha$-tocopheryl acetate-enriched diet ( $E_{\text {all }}$-rad $)$. The effect of the activity of dietary natural and synthetic $\alpha$-tocopheryl acetates in pigs has been studied by Lauridsen et al. (2002), who suggested that $\alpha$-tocopherol with its natural stereochemistry is twice as effective at maintaining plasma $\alpha$-tocopherol concentrations in pigs as synthetic $\alpha$-tocopherol, which contains eight different stereoisomers. These authors also demonstrated that pigs discriminate between $R R R$ - and all-rac- $\alpha$-tocopherols with a preference for natural, $R R R-\alpha$ tocopherol. These findings could be related to the lower TBARS values in meat from pigs fed supplemented natural $\alpha$-tocopherol as already discussed above.

Finally, meat from pigs fed with the $A_{\text {Flav }} A_{\text {phen }}$ and control concentrated diets presented similar TBARS values during refrigerated storage, but significantly higher $(P<0.01)$ TBARS on days 3, 7 and 10 than free-range and $\alpha$-tocopherol-enriched diets. Hence, the administration of the two commercial flavonoid and phenolic-enriched extracts did not decrease the lipid oxidation in the meat. This could be because the phenolic compounds present in the commercial extracts are not absorbed and accumulated in the meat or because these commercial extracts have no antioxidant activity in pig meat when they are incorporated into concentrated feed. As Cantos et al. (2003) suggested, further studies are needed concerning the metabolism of these polyphenols, the possible types of metabolites absorbed, and their accumulation in the different tissues of the pig. 
It is concluded that feeding Iberian pigs in confinement with $200 \mathrm{mg} / \mathrm{kg}$ diet of natural $R R R-\alpha$-tocopherol extract produced similar antioxidant content in the muscle as those fed under free-range conditions and higher than pigs fed on $200 \mathrm{mg} / \mathrm{kg}$ diet of synthetic all-rac- $\alpha$-tocopheryl acetate concentrate diet. $A_{\text {Flav }}$ and $A_{\text {phen }}$ gave a similar antioxidant content as the control diet. In summary, the TBARS values in refrigerated storage meats from free-range and $R R R-\alpha-$ tocopherol pigs were lower than those corresponding to the other diets supplemented with antioxidant extracts. Supplementation of concentrated diets with $\alpha$-tocopherol from natural sources seems to be a more effective defence against lipid oxidation in muscle than synthetic $\alpha$-tocopheryl acetate. The commercial flavonoid and phenolic extracts used in this work did not show any valuable influence on antioxidant content and lipid oxidation levels in the meat.

\section{Acknowledgements}

The authors are grateful to 'Nutrición Especial S.L.' for the financial support of this work and to Alejandro Hernández, Mercedes Cortés and Gonzalo Fructuoso for their technical assistance.

\section{References}

Association of Official Analytical Chemists 1984. Official methods of analysis. AOAC, Arlington, VA, USA.

Bligh EG and Dyer WJ 1959. A rapid method of total lipid extraction and purification. Canadian Journal of Biochemistry and Physiology 37, 911-917.

Buckley DJ, Gray Jl, Asghar A, Price JF, Crackel RL, Booren AM, Pearson AM and Miller ER 1989. Effect of dietary antioxidants and oxidized oil on membranal lipid stability and pork product quality. Journal of Food Science 54, 1193-1197.

Buckley DJ, Morrisey PA and Gray JI 1995. Influence of dietary vitamin E on the oxidative stability and quality of pig meat. Journal of Animal Science 73 , 3122-3130.

Buttris JL and Diplock AT 1984. High-performance liquid chromatography methods for vitamin $E$ in tissues. Methods in Enzymology 105, 131-138.

Cantos E, Espín JC, López-Bote C, De la Hoz L, Ordóñez JA and TomásBarberán FA 2003. Phenolic compounds and fatty acids from acorns (Quercus spp.), the main dietary constituent of free-ranged Iberian pigs. Journal of Agricultural and Food Chemistry 51, 248-6255.

Carrapiso Al, Ventanas J and García C 2002. Characterization of the most odor active compounds of Iberian ham headspace. Journal of Agricultural and Food Chemistry 50, 1996-2000.

Cava R, Ruiz J, López-Bote CJ, Martín L, García C, Ventanas J and Antequera T 1997. Influence of finishing diet on fatty acid profiles of intramuscular lipids, triglycerides and phospholipids in muscles of the Iberian pig. Meat Science 45 , 263-270.

Cava R, Ruiz J, Ventanas J and Antequera T 1999. Oxidative and lipolytic changes during ripening of Iberian hams as affected by feeding regime: extensive feeding and alpha-tocopheryl acetate supplementation. Meat Science 52, 165-172.

Cava R, Ventanas R, Tejeda JF, Ruiz J and Antequera T 2000. Effect of freerange rearing and $\alpha$-tocopherol and copper supplementation on fatty acid profiles and susceptibility to lipid oxidation of fresh meat from Iberian pigs. Food Chemistry 68, 51-59.

Cherian G, Wolfe FW and Sim JS 1996. Dietary oils with added tocopherols, effects on egg or tissue tocopherols fatty acids and oxidative stability. Poultry Science $75,423-431$.
Daza A, Rey Al, Ruiz J and López-Bote CJ 2005. Effects of feeding in free-range conditions or in confinement with different dietary MUFA/PUFA ratios and $\alpha$-tocopheryl acetate, on antioxidants accumulation and oxidative stability in Iberian pigs. Meat Science 69, 151-163.

Estévez M, Morcuende D and Cava R 2006. Extensively reared lberian pigs versus intensively reared white pigs for the manufacture of frankfurters. Meat Science 72, 356-364.

Fuhrmann H and Sallman HP 1996. Phospholipid fatty acid of brain and liver are modified by $\alpha$-tocopherol and dietary fat in growing chicks. British Journal of Nutrition 79, 109-122.

González E, Tejeda JF, Moltiva MJ and Romero MP, 2004. Phenolic compounds in subcutaneous adipose tissue from Iberian pigs. Proceedings of the fifth international symposium of the Mediterranean pig, Tarbes, France, pp. 31-32.

González E, Velardo B and Tejeda JF 2006. Comparison between two different levels of replacement of free-range rearing by an oleic acid and $\alpha$-tocopherol enriched diet on the quality of fresh meat from Iberian $\times$ Duroc $(50 \%)$ pigs. Food Science and Technology International 12, 57-66.

Lauridsen C, Engel H, Craig AM and Traber MG 2002. Relative bioactivity of dietary RRR- and all-rac-alpha-tocopheryl acetates in swine assessed with deuterium-labeled vitamin E. Journal of Animal Science 80, 702-707.

López MO, De la Hoz L, Cambero MI, Gallardo E, Reglero G and Ordóñez JA 1992. Volatile compounds of dry hams from Iberian pigs. Meat Science 31, 267-277.

López-Bote CJ 1998. Sustained utilization of the Iberian pig breed. Meat Science 49, S17-S27.

López-Bote CJ, Rey Al, Isabel B and Sanz R 1997. Effects of feeding diets high in monounsaturated fatty acids and $\alpha$-tocopheryl acetate to rabbits on resulting carcass fatty acid profile and lipid oxidation. Animal Science 64 , 177-186.

López-Bote CJ, Isabel B, Ruiz J and Daza A 2003. Effect of vitamin E supplementation and partial substitution of poly- with mono-unsaturated fatty acids in pigs diets on muscle, and microsome extract $\alpha$-tocopherol concentration and lipid axidation. Archives of Animal Nutrition 57, 11-25.

Madsen HL and Bertelsen G 1955. Spices as antioxidants. Trends in Food Science and Technology 6, 271-277.

Monahan FJ, Gray Jl, Booren AM, Miller ER, Bucley DJ and Morrisey PA 1992. Influence of dietary treatment on cholesterol oxidation in pork. Journal of Agricultural and Food Chemistry 40, 1310-1315.

Morrisey PA, Sheehy PJA, Galvin K, Kerry JP and Buckley D 1998. Lipid stability in meat and meat products. Meat Science 49, 73-86.

Muriel E, Ruiz J, Ventanas J and Antequera T 2002. Free-range rearing increases $(n-3)$ polyunsaturated fatty acids of neutral and polar lipids in swine muscles. Food Chemistry 78, 219-225.

Okayasu T, Kameda K, Ono T and Imai $Y$ 1977. Effect of dietary vitamin $B_{2}$ and vitamin $\mathrm{E}$ on the $\Delta$-9-desaturase and catalase activities in rat liver microsomes. Biochimica and Biophysica Acta 489, 389-402.

Rey Al and López-Bote CJ 2001. Effect of dietary copper and vitamin E supplementation, and extensive feeding with acorns and grass on longissimus muscle composition and susceptibility to oxidation in Iberian pigs. Journal of Animal Physiology and Animal Nutrition 85, 281-292.

Rey A, López-Bote CJ, Soares J and Isabel B 1996. Determination of $\alpha$-tocopherol in pork with high intramuscular fat content. Grasas y Aceites $47,331-334$.

Rey Al, Isabel B, Cava R and López-Bote CJ 1998. Dietary acorns provide a source of gamma-tocopherol to pigs raised extensively. Canadian Journal of Animal Science 78, 441-443.

Rey Al, Kerry JP, Lynch PB, López-Bote CJ, Buckley DJ and Morrissey PA 2001. Effect of dietary oils and $\alpha$-tocopheryl acetate supplementation on lipid (TBARS) and cholesterol oxidation in cooked pork. Journal of Animal Science 79, 1201-1208.

Rey Al, López-Bote CJ, Kerry JP, Lynch PB, Buckley DJ and Morrisey PA 2004. Modification of lipid composition and oxidation in porcine muscle and muscle microsomes as affected by dietary supplementation of $n-3$ with either $n-9$ or $n-6$ fatty acids and $\alpha$-tocopheryl acetate. Animal Feed Science and Technology 113, 223-238.

Ruiz J, García C, Muriel E, Andrés Al and Ventanas J 2002. Influence of sensory characteristics on the acceptability of dry-cured ham. Meat Science 61 , 347-354. 
Schwarz K, Bertelsen G, Nissen LR, Gardener PT, Heinonen MI, Hopia A, Huynh-Ba T, Lambelet P, McPhail D, Skibsted LH and Tijburg L 2001. Investigation of plant extracts for the protection of processed foods against lipid oxidation. Comparison of antioxidant assays based on radical scavenging, lipid oxidation and analysis of the principal antioxidant compounds. European Food Research and Technology 212, 319-328.

Salih AM, Smith DM, Price JF and Dawson LE 1987. Modified extraction 2-thiobarbituric acid method for measuring lipid oxidation in poultry. Poultry Science $66,1483-1489$.

Skerget M, Kotnik P, Hadolin M, Rizner A, Simonic M and Knez Z 2005. Phenols, proanthocyanidins, flavones and flavonols in some plant materials and their antioxidant activities. Food Chemistry 89, 191-198.
Statistical Packages for the Social Sciences 2003. SPSS Base 11.5. User manual: application guide. SPSS Inc., Chicago, IL.

Tejeda JF, Gandemer G, Antequera T, Viau M and García C 2002. Lipid traits of muscles as related to genotype and fattening diet in Iberian pigs: total intramuscular lipids and triacylglycerols. Meat Science 60, 357-363.

Vázquez A, Janer C and Janer ML 1973. [Determinación de los polifenoles totales en aceite de oliva.]. Grasas y Aceites 24, 350-357.

Ventanas S, Estévez M, Tejeda JF and Ruiz J 2006. Protein and lipid oxidation in longissimus dorsi and dry cured loin from Iberian pig as affected by crossbreeding and diet. Meat Science 72, 647-655.

Vitamin E Research and Information Service 1997. Studies of lipid-soluble antioxidants. VERIS, LaGrange, IL, USA. 